\title{
A autoeficácia no desenvolvimento de carreira e sua influência na diversidade de gênero na computação
}

\author{
Self-efficacy in career development and its influence on \\ gender diversity in computer science
}

Karen da Silva FIGUEIREDO' 1

Cristiano MACIEL ${ }^{2}$

\begin{abstract}
Resumo
Entender como a autoeficácia na computação é percebida pelas adolescentes ajuda a compreender as experiências que vivenciam em busca da diversidade de gênero na área. Objetiva-se discutir sobre como os gêneros influenciam na decisão profissional das adolescentes por seguirem carreiras e cursos de computação a partir da Psicologia do desenvolvimento da carreira e do papel da autoeficácia. Este artigo apresenta a construção da Escala de Autoeficácia em Tecnologias e Computação para estudantes de ensino médio e sua pilotagem com 14 alunas na qual observou-se uma baixa autoeficácia na tomada de decisão por cursos e nos conhecimentos de computaçáo pelas alunas.
\end{abstract}

Palavras-chave: Autoeficácia. Desenvolvimento de Carreira. Diversidade de Gênero. Computação e Tecnologias.
Abstract

Understanding how self-efficacy in computer science is perceived by adolescents helps to understand the experiences they live, in pursuit of gender diversity in computing. This paper aims to discuss about how the genders could influence in the career choice of the adolescents from the view of the career development Psychology and the self-efficacy's role. This article presents the construction of the self-efficacy scale in computer science and technologies for high school students and its validation through a pilot application with 14 female students. Preliminary results show low self-efficacy in their higher education decision-making process and in their computer science knowledge.

Keywords: Self-efficacy. Career Development. Gender Diversity. Computer Science and Technologies.

1 Mestre em Computação pela Universidade Federal Fluminense. Pesquisadora no Laboratório de Estudos sobre Tecnologias da Informação e Comunicação na Educação. Professora no Instituto de Computação da Universidade Federal de Mato Grosso, situado na Av. Fernando Corrêa da Costa, n. ${ }^{\circ} 2367$, Boa Esperança, Cuiabá-MT, CEP: 78060-900, Tel.: (65) 3615-8791. Email: <karen@ic.ufmt.br>.

2 Doutor em Computação pela Universidade Federal Fluminense. Pesquisador no Laboratório de Estudos sobre Tecnologias da Informação e Comunicação na Educaçáo e do Laboratório de Ambientes Virtuais Interativos. Professor no Instituto de Computação e do Programa de Pós-graduação em Educaçáo da Universidade Federal de Mato Grosso, situado na Av. Fernando Corrêa da Costa, n. ${ }^{2} 2367$, Boa Esperança, Cuiabá-MT, CEP: 78060-900, Tel.: (65)3615-8791. Email: <cmaciel@ufmt.br>.

\begin{tabular}{|l|l|l|l|l|l|} 
R. Educ. Públ. & Cuiabá & v. 27 & n. 65/1 & p. 365-384 & maio/ago. 2018 \\
\hline
\end{tabular}




\section{Introdução}

A autoeficácia é um mecanismo de avaliação individual do quanto uma pessoa acredita que pode (é capaz de) realizar determinada atividade, dentro de um domínio de funcionalidade. Assim, crenças de autoeficácia representam como as pessoas percebem as suas capacidades de organizar e executar açóes necessárias para alcançar determinado tipo de resultado (BANDURA, 1986).

Estudos sobre a autoeficácia mostram como ela está relacionada com a receptividade da diversidade nos ambientes de estudo e trabalho (BEHJAT; CHOWDHURY, 2013; CHOI; PRICE; VINOKUR, 2003), enquanto outros mostram que vivências de diversidade podem aumentar a autoeficácia dos indivíduos na execução de tarefas (COMBS; LUTHANS, 2007; KARWOWSKI; KAUFMAN, 2017;). Na Psicologia do desenvolvimento de carreira, a autoeficácia é uma das categorias de análise mais importantes e que tem recebido maior atenção nas pesquisas da área, muito embora os trabalhos que exploram essa temática no contexto brasileiro ainda sejam incipientes (PRISCO; MARTINS; NUNES, 2013).

Conhecida popularmente como uma área dura da ciência, a computação ainda é uma área que carece de diversidade no perfil de seus estudantes e profissionais. No Brasil, os dados apontam que a presença feminina em cursos de ensino superior da área de computação e tecnologias é muito baixa quando comparada a outras áreas (PORTAL BRASIL, 2015). Em 1991, as mulheres somavam 34,9\% dos alunos matriculados em cursos de ensino superior de computaçáo e suas tecnologias; em 2013, passaram a representar $15,53 \%$ dos ingressantes, e dessas, apenas $13,6 \%$ concluem o curso, segundo o Censo da Educação Superior (INEP, 2015).

Entretanto, pesquisas mostram que o número de crianças e adolescentes de ambos os gêneros que se interessam por essas áreas de conhecimento é praticamente idêntico até os 13 anos de idade (SAAVEDRA et al., 2010). A partir dos 13 anos, é possível verificar o decréscimo no número de adolescentes do gênero feminino que escolhem esse domínio tipicamente masculino, em todos os níveis de ensino subsequentes.

Entender como a autoeficácia relacionada ao domínio da computação e suas tecnologias e à escolha profissional é percebida pelas adolescentes pode ajudar a compreender as experiências que elas vivenciam em busca da diversidade de gênero na área de computação.

Diante do exposto, o objetivo deste artigo é discutir como os gêneros podem influenciar nas tomadas de decisão profissional das adolescentes por seguirem carreiras e cursos de ensino superior em computação e tecnologias a partir de uma perspectiva teórica da Psicologia do desenvolvimento da carreira e do papel da autoeficácia. 
Assim, este artigo apresenta a construção da Escala de Autoeficácia em Tecnologias e Computação (EATEC), uma escala voltada para estudantes de ensino médio com o intuito de medir sua confiança em aspectos da tomada de decisóes por curso superior, com ênfase na computação e seu relacionamento com tecnologias no dia a dia. A EATEC foi elaborada a partir de uma análise do domínio, seguindo os princípios teóricos descritos por Bandura (2006) para a construçáo desse tipo de instrumento. Uma aplicação piloto da escala com 14 estudantes de ensino médio foi realizada para verificar a sua confiabilidade.

A partir dessa introdução, este artigo está organizado da seguinte forma: a seção 2 traça uma discussão teórica sobre os entrelaçamentos dos estudos de gênero com a Psicologia do desenvolvimento da carreira, desde as teorias empiristas até a teoria sociocognitiva da carreira adotada neste trabalho; a seção 3 introduz os conceitos da Teoria sociocognitiva da carreira e um dos seus elementos principais: a autoeficácia; a seção 4 aborda a autoeficácia e sua importância nas dimensóes da carreira e do gênero; na seção 5 é descrito o processo de elaboração da escala de autoeficácia EATEC e os resultados preliminares da aplicação da escala; por fim, na seçáo 6 as conclusóes e os trabalhos futuros são discutidos.

\section{Estudos de gênero e Psicologia do desenvolvimento da carreira}

$\mathrm{Na}$ Psicologia moderna é possível encontrar pesquisas com diferentes posturas teóricas e posicionamentos epistemológicos no domínio dos estudos de gênero. Taveira e Nogueira (2004) apresentam três tipos de perspectivas teóricas da Psicologia, baseadas na tipologia dos modelos de crítica feminista à ciência estruturada por Harding (1986), a saber: a perspectiva empirista, a perspectiva de "standpoint" feminista e a perspectiva pós-moderna.

A perspectiva empirista, também conhecida como paradigma tradicional, e ainda predominante na Psicologia, tem como característica a objetividade e possui duas abordagens principais: a essencialista e a de ênfase na socializaçâo. $\mathrm{Na}$ abordagem essencialista, que prevalece na primeira metade do século XX, sexo e gênero aparecem como equivalentes e os estudos apontam diferenças inatas e estáveis entre homens e mulheres. Assim, o gênero é considerado uma propriedade estável, inata e bipolar, de caráter determinista, apenas para diferenciação sexual (TAVEIRA; NOGUEIRA, 2004). Nessa perspectiva, homens e mulheres são, por natureza, aptos para determinadas atividades, cabendo aos homens o trabalho duro e intelectual e às mulheres o cuidado do lar, dos filhos e profissóes que remetam a esse tipo de atividade. 
Já a abordagem de ênfase na socialização, que dominou a Psicologia Social das décadas de 60 e 70, propóe a socialização do gênero, que deixa de ser concebido como inato e passa a ser reconhecido como o resultado de forças sociais e culturais. A masculinidade e a feminilidade são vistas nessa abordagem como características socialmente aprendidas, de acordo com o que é apropriado para as normas da sociedade.

Apesar de enfatizar que o gênero é aprendido e não inato, a diferença entre inato e aprendido limita-se à semântica, ao considerar que as fontes de socialização e o sistema social das relações de gênero são pouco discutidos e questionados (AMÂNCIO, 1992) e que o gênero aparece de forma praticamente imutável ao longo da vida (TAVEIRA; NOGUEIRA, 2004). A socialização dos papéis de gênero toca a dimensão da carreira, determinando os universos de profissóes do masculino e do feminino, estando o conhecimento científico e tecnológico associados ao universo do masculino.

A perspectiva de "standpoint" feminista emergiu nas décadas de 70 e 80 , distanciando-se da busca por objetividade e neutralidade da abordagem empirista, centralizando os estudos, que na maioria das vezes eram escritos por mulheres, nas mulheres e nas suas experiências particulares. Nessa perspectiva, os estereótipos sociais sobre o feminino são rejeitados e, como estratégia de fuga dos estereótipos, os estudos celebram uma natureza especial das mulheres, consequentemente, enfatizando mais do que negando diferenças inatas entre os sexos (HARTSOCK, 1990).

Algumas abordagens da perspectiva de "standpoint" feminista tentam reaproximar as mulheres da tecnologia em suas opçóes de carreira, todavia, por meio de analogias e eufemismos sobre a conexão da natureza feminina com a tecnologia. Assim, resgatam novamente a predisposiçáo para o cuidado e o trabalho manual como elemento da mulher, fazendo alusão, por exemplo, às redes tecnológicas com teares artesanais, aos trabalhos repetitivos em montagens como apropriados para a delicadeza feminina e às maquinarias como organismos que precisam de cuidados especiais (PLANT, 1993).

Por sua vez, na perspectiva pós-moderna, que aparece nos trabalhos a partir da década de 80, o gênero começa a ser investigado como uma construção social, como produto ideológico emergente das relaçóes e dos discursos da sociedade. Essa perspectiva desafia o caráter natural das diferenças de gêneros e sustenta que todas as características sociais significativas dos gêneros são ativamente construídas e não biológicas, permanentemente socializadas ou estruturalmente impostas, como nas perspectivas anteriores (TAVEIRA; NOGUEIRA, 2004).

Seguindo o desenvolvimento das perspectivas teóricas sobre gêneros na Psicologia moderna, é possível notar a evolução com o passar do tempo da forma 
como os gêneros são tratados nas teorias da Psicologia do desenvolvimento da carreira.

Até da década de 60, observa-se a perspectiva vocacional dos traços, de caráter empirista e essencialista, que atribui grande importância às características e traços estáveis da personalidade (como os interesses e aptidóes) e náo faz distinção entre sexo e gênero (BROWN, 2002). Esses estudos de desenvolvimento da carreira focam nas diferenças entre escolhas de cursos e profissóes por homens e mulheres sem discutir porque ou como essas decisóes são tomadas, quase subentendendo que haja uma causa natural para isso, fortalecendo, assim, estereótipos sociais relacionados aos gêneros.

Após a década de 60 , surge a perspectiva desenvolvimentista da carreira, que começa a abordar as bases psicológicas dos processos de tomada de decisáo relacionados à carreira, trajetória e subjetividade da vida profissional, bem como a relação entre formação, trabalho e demais dimensóes da vida. A visão sobre a carreira na perspectiva desenvolvimentista enfatiza o estudo do desenvolvimento individual relacionado à carreira, caracterizado pela mutabilidade. A noção de carreira passa a ser um conceito centrado na pessoa e não tanto na escolha da carreira, como na perspectiva anterior.

Embora a maior parte das pesquisas tivessem suas raízes na perspectiva psicológica empirista e de socialização do gênero, alguns trabalhos já abriam as portas para a incorporação das perspectivas "standpoint" feminista e pós-moderna, mostrando como os valores culturais e as relaçóes sociais assumem um papel importante no desenvolvimento da carreira, com impactos distintos para homens e mulheres (BROWN, 2002).

É importante ressaltar ainda que muito da linha desenvolvimentista avançou com análise principalmente da trajetória masculina. Como consequência, surgem modelos conceituais específicos para descrever a carreira das mulheres, em que se destacam os papéis familiares que desempenham (FITZGERALD; FASSINGER; BETZ, 1995). Porém, o aumento do número de mulheres trabalhando fora de casa fez desaparecer esse conjunto de trabalhos, dando lugar para os estudos que procuram diferenciar as mulheres que escolhem profissóes tradicionais daquelas que escolhem profissóes em domínios tradicionalmente associados aos homens.

Estudos da década de 80 sugerem que diferentes experiências de socialização dos homens e das mulheres dão origem a um padrão mais complexo do desenvolvimento da carreira das mulheres (DEAUX, 1984). Inicia-se a discussáo sobre a existência de barreiras, internas e externas, com as quais as mulheres se confrontam, tais como a baixa autoeficácia acadêmica, a existência de poucos modelos femininos e poucas oportunidades, o conflito casa-carreira, entre outros.

$\mathrm{Na}$ década de 90, como parte da linha de estudo desenvolvimentista, emerge 
uma nova perspectiva teórica: a perspectiva sociocognitiva da carreira, cunhada por Lent, Brown e Hackett (1994). Essa perspectiva considera os processos autorreflexivos, que incluem percepçóes e significados mais íntimos que as pessoas constroem e exibem sobre as suas próprias capacidades e competências, bem como sobre os acontecimentos e náo acontecimentos da sua vida e carreira, e que determinam o comportamento de carreira ao longo da vida, tanto das mulheres, como dos homens.

A perspectiva sociocognitiva da carreira marca um avanço considerável na abordagem de gênero em relaçáo à carreira, evidenciando o papel que fatores contextuais dos ambientes, desde os mais próximos (família, escola, ambientes de trabalho e comunidade), até os mais distantes (governo e políticas sociais, educativas, econômicas), desempenham na construção individual e social do gênero e no comportamento e desenvolvimento de carreira. Diferente das perspectivas antecedentes, as escolhas de carreira dos indivíduos são estudadas considerando os múltiplos contextos dos quais fazem parte e características que carregam (gênero, raça-etnia, estados de saúde, etc.), como uma malha de conexôes e náo como pontos de decisóes isolados.

Dessa forma, por se tratar de uma teoria abrangente com relação às influências dos gêneros e demais fatores internos e externos na carreira, a Teoria Sociocognitiva do Desenvolvimento da Carreira de Lent, Brown e Hackett $(1994,2002)$ é a teoria adotada como âncora teórica deste trabalho e descrita na seção a seguir.

\section{A Teoria Sociocognitiva da Carreira}

A Teoria Sociocognitiva da Carreira (LENT; BROWN; HACKETT, 2002), do original em inglês Social Cognitive Career Theory, complementa e constitui ligaçóes conceituais com outras teorias de desenvolvimento da carreira, abrangendo definiçóes cognitivas e construtivistas sobre as capacidades humanas de influenciar seu próprio desenvolvimento e meio (e ser influenciadas por ele).

A Teoria Sociocognitiva da Carreira não faz distinção entre interesses, escolhas e desempenhos acadêmicos ou de carreira (LENT; BROWN; HACKETT, 2002), ou seja, quando articula sobre carreira, está incluindo também a dimensão acadêmica. Neste trabalho, adota-se essa mesma perspectiva.

As teorias de carreira anteriores utilizavam como base a aprendizagem social (BANDURA, 1969) e a Teoria Sociocognitiva da Carreira foca na aprendizagem cognitiva, com um viés construcionista. A sua base teórica principal é a teoria social cognitiva da aprendizagem (BANDURA, 1986, 1999), que considera a existência de uma relação mútua de troca entre indivíduo e ambiente, segundo as 
inter-relações da tríade do determinismo recíproco (ilustradas na Figura 1) entre: fatores pessoais, como estados afetivos e cognitivos e características físicas; fatores comportamentais; e fatores ambientais. Com esse sistema tríade, as pessoas são produtoras e produtos dos seus ambientes, e isso afeta todas as dimensôes da vida, inclusive a carreira.

Figura 1 - Tríade do determinismo recíproco

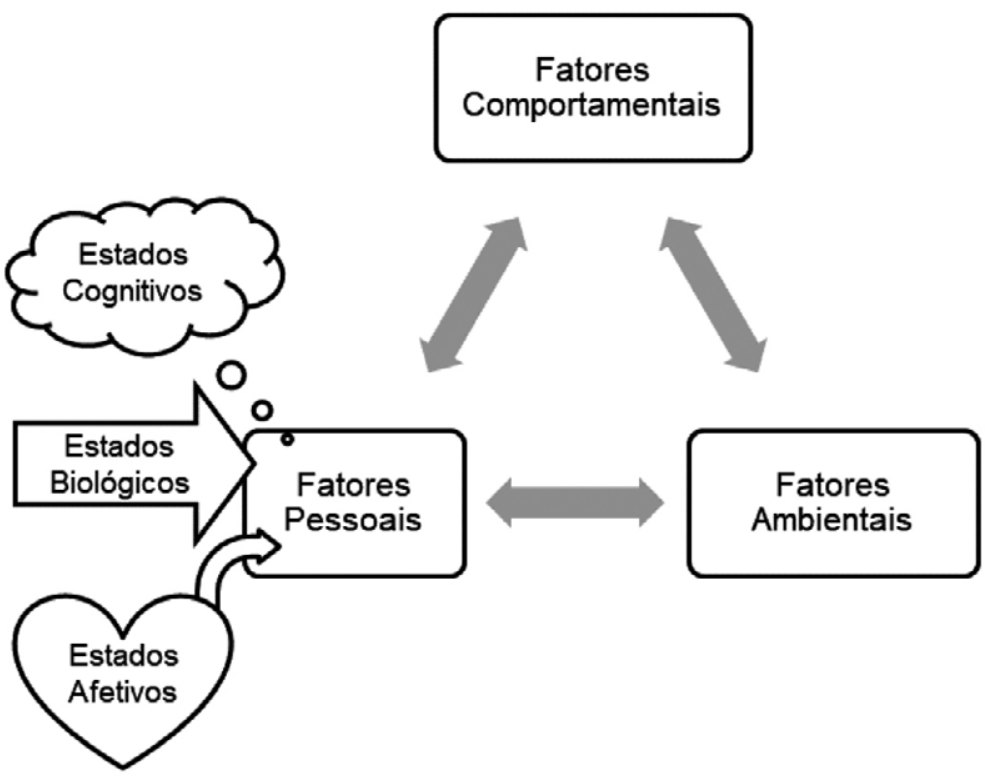

Fonte: Traduzida e adaptada de BANDURA (1986).

Ponderando sobre isso, Lent, Brown e Hackett adaptaram, elaboraram e estenderam os aspectos da teoria de Bandura $(1986,1989,1999)$ que pareceram ser mais relevantes para o processo de formação de interesses, seleção de carreira e desempenho profissional, incorporando três variáveis centrais dessa teoria: a autoeficácia, as expectativas de resultado e os objetivos pessoais. $\mathrm{Na}$ Teoria Sociocognitiva da Carreira essas variáveis são vistas como blocos construtores básicos do desenvolvimento da carreira e representam mecanismos centrais pelos quais os indivíduos são capazes de moldar e exercitar seu ativismo pessoal.

Das três, a autoeficácia é a mais importante e foi a que recebeu a maior atenção na literatura de carreira (LENT; BROWN; HACKETT, 2002). A autoeficácia refere-se às crenças dos indivíduos sobre suas "[...] capacidades de organizar e executar sequências de açóes necessárias para alcançar determinados tipos de 
desempenho" (BANDURA, 1986, p. 391). Aplicando esse conceito no domínio deste trabalho, a autoeficácia das adolescentes em executar atividades no campo da tecnologia e ter um bom resultado reflete o quanto elas acreditam que isso seja possível de ser feito por elas.

As crenças de autoeficácia são adquiridas e modificadas via quatro fontes principais baseadas em experiências de aprendizagem ${ }^{3}$ (BANDURA, 1995), de acordo com as descriçóes do Quadro 1.

Quadro 1 - Fontes de Autoeficácia

\begin{tabular}{|l|l|l|}
\hline $\begin{array}{l}\text { Fontes de } \\
\text { Autoeficácia }\end{array}$ & \multicolumn{1}{|c|}{ Descrição } & \multicolumn{1}{c|}{ Exemplo } \\
\hline $\begin{array}{l}\text { Experiências } \\
\text { pessoais }\end{array}$ & $\begin{array}{l}\text { Vivências pessoais } \\
\text { passadas, podem ser } \\
\text { positivas ou negativas }\end{array}$ & $\begin{array}{l}\text { Experiências positivas e negativas das } \\
\text { adolescentes, enquanto realizando atividades } \\
\text { do domínio tecnológico/computacional }\end{array}$ \\
\hline $\begin{array}{l}\text { Experiências } \\
\text { vicárias }\end{array}$ & $\begin{array}{l}\text { Aprendizagem baseada } \\
\text { na observação de } \\
\text { resultados obtidos por } \\
\text { outras pessoas }\end{array}$ & $\begin{array}{l}\text { Observação das adolescentes de experiências } \\
\text { e resultados, positivos e negativos, obtidos } \\
\text { por outras pessoas no domínio tecnológico/ } \\
\text { computacional }\end{array}$ \\
\hline Persuasão social & $\begin{array}{l}\text { Encorajamento e } \\
\text { desencorajamento } \\
\text { provenientes de outras } \\
\text { pessoas }\end{array}$ & $\begin{array}{l}\text { O quanto de incentivo as adolescentes recebem } \\
\text { para realizar atividades do domínio tecnológico/ } \\
\text { computacional }\end{array}$ \\
\hline $\begin{array}{l}\text { Estados físicos, } \\
\text { afetivos e } \\
\text { cognitivos }\end{array}$ & $\begin{array}{l}\text { Conjunto de sensações } \\
\text { percebidas pelos } \\
\text { indivíduos e seus corpos }\end{array}$ & $\begin{array}{l}\text { Como as adolescentes sentem-se ao } \\
\text { realizar atividades do domínio tecnológico/ } \\
\text { computacional e com que outros tipos de } \\
\text { experiências elas associam esses estados }\end{array}$ \\
\hline
\end{tabular}

Fonte: Elaboração dos autores

Embora os efeitos dessas fontes dependam de uma série de fatores, as experiências pessoais são vistas como a fonte mais potente de autoeficácia, pois a vivência de sucesso em determinada tarefa ou domínio de desempenho tende a aumentar a autoeficácia, enquanto falhas repetitivas a reduzem (LENT; BROWN; HACKETT, 2002). Nesse sentido, a falta de acesso e contato com tecnologia e atividades associadas para as meninas dificulta o desenvolvimento de uma autoeficácia positiva para elas nesse domínio, fato que geralmente acontece considerando fatores socioculturais em que são criadas. Assim como observar

3 Segundo Bandura (1999), experiências de aprendizagem acontecem em momentos nos quais as pessoas vivenciam os efeitos das suas açóes ou via poder da modelagem social. 
experiências negativas de outras meninas e a falta de incentivo e estados de ansiedade ao realizar uma tarefa na área podem também contribuir negativamente para o desenvolvimento da autoeficácia das adolescentes.

As expectativas de resultado são crenças pessoais sobre as consequências ou resultados de determinados comportamentos. Enquanto a autoeficácia foca nas capacidades das pessoas, as expectativas de resultado envolvem a imaginação das consequências de executar determinado comportamento, por exemplo, uma adolescente que não tem contato com atividades computacionais pode acreditar que se ela tentar fazer algo nessa área terá resultados negativos, e assim não irá tentar.

As expectativas de resultado exercem papel principal na motivação de comportamentos e envolvem crenças de reforço e recompensa, crenças sobre a realização da ação em si e sobre as consequências para a pessoa. Essas crenças são adquiridas por meio de experiências de aprendizagem similares às crenças de autoeficácia e são, também, influenciadas por ela quando os resultados são determinados pela qualidade do desempenho (LENT; BROWN; HACKETT, 2002).

Os objetivos pessoais estáo presentes em todas as teorias de carreira e são definidos como "[...] a determinação para engajar em uma atividade particular ou para efetuar determinado resultado futuro" (LENT; BROWN; HACKETT, 2002, p. 263). As crenças de autoeficácia e de expectativas de resultado afetam os objetivos que são selecionados e o esforço gasto em buscar alcançar esses objetivos. Em contrapartida, influenciam o desenvolvimento da autoeficácia e das expectativas de resultado, já que permanecer em um objetivo pode melhorar a autoeficácia e as expectativas de resultado.

Assim, uma jovem que possui baixa autoeficácia no domínio tecnológico e possui expectativas de resultado negativas quanto a executar uma atividade pode não criar o objetivo pessoal de se engajar nesse tipo de atividade, da mesma forma que uma jovem que esteja engajada o suficiente em fazer um curso de computação, por exemplo, pode elevar a sua autoeficácia e gerar expectativas de resultados positivos ao permanecer no curso e viver experiências de aprendizagem positivas para ela nesse domínio.

\section{0 papel da autoeficácia}

Crenças de eficácia refletem avaliaçóes de capacidade. A autoeficácia representa o quanto um indivíduo acredita que pode (é capaz de) realizar determinada atividade, dentro de um domínio de funcionalidade. A autoeficácia percebida está relacionada "[...] às crenças de pessoas nas suas capacidades de produzirem determinados resultados" (BANDURA, 1999, p. 46). 
A autoeficácia influencia as pessoas a pensarem erraticamente e estrategicamente, de forma otimista ou pessimista. Esse conjunto de crenças atua nas escolhas, nos desafios e nos objetivos que as pessoas traçam para si, nos seus níveis de compromisso e de esforço para realizar determinados empreendimentos, nos resultados que esperam dos esforços produzidos e o quanto perseveram diante de obstáculos. Também influencia suas resiliências a adversidades, a qualidade das suas vidas emocionais e o quanto de estresse e depressão elas experienciam ao lidar com demandas taxativas do ambiente, com as escolhas de vida que fazem e com os feitos que realizam (BANDURA, 2006).

Toda extensão da influência da autoeficácia então descrita pode ser pensada na dimensão da carreira. A autoeficácia tem sido o tópico individual mais popular de investigação nas pesquisas de Psicologia de desenvolvimento da carreira. Muitos estudos examinam a relação da autoeficácia com interesses, indicadores de desempenho, entre outras variáveis (DUCHATELET et al., 2016; HUANG, 2013). Outros estudos, assim como este, examinam as diferenças de gêneros relacionadas à autoeficácia na carreira (TIMS; BAKKER; DERKS, 2014).

Compreender a relação das adolescentes com sua autoeficácia durante o ensino médio e últimos anos da adolescência é importante para o desenvolvimento de métodos que fomentam a autoeficácia durante os anos escolares, quando a autopercepção e as crenças de carreira dos adolescentes tendem a ser mais maleáveis, um pouco antes de estabilizarem (ROJEWSKI; YANG, 1997).

Segundo a Teoria Sociocognitiva da Carreira, tais métodos devem garantir que as crenças de autoeficácia dos adolescentes sejam relativamente coerentes com suas habilidades em desenvolvimento, e não construídas baseadas em informaçóes imprecisas e percepçóes equivocadas, uma vez que os adolescentes tendem a desenvolver crenças de eficácia irreais, por exemplo, comparando suas conquistas em um domínio com as conquistas de um adulto já profissional na área (LENT; BROWN; HACKETT, 2002). No caso da tecnologia, percebe-se que há a necessidade de desenvolver açóes para que as meninas tenham contato com esse domínio, ações afirmativas para a inclusão das adolescentes nesse setor e a divulgação de informaçóes sobre a área e role models femininos para inspirá-las a desenvolverem uma autoeficácia positiva com relação à área.

Além da faixa etária, as crenças de autoeficácia também estão presentes de formas diferentes entre os gêneros. As relaçóes entre os gêneros e a socialização dos papéis de gênero tendem a enviesar o acesso às fontes de eficácia, fortalecendo a autoeficácia para atividades tradicionalmente femininas, mas limitando a autoeficácia em domínios não tradicionais, como é o caso da computação e tecnologias em geral (BETZ; HACKETT, 1981), domínio cujas condiçóes socioeconômicas e culturais de mulheres geralmente não favorecem fontes de autoeficácia positivas, conforme discutido na seção anterior. 
Assim, a busca pela carreira das adolescentes pode ser restringida pelos efeitos limitadores da baixa autoeficácia, considerando que as barreiras impostas pelo ambiente (e.g. $g^{4}$ cultura, falta de oportunidades, etc.) podem ser internalizadas na forma de viés nas crenças de autoeficácia. Portanto, a análise da autoeficácia é útil para promover sistemas de apoio sem estereótipos de gênero em domínios de desempenho não tradicionais (LENT; BROWN; HACKETT, 2002), como é o caso da área de computação e suas tecnologias.

\section{Medindo a autoeficácia}

O método tradicional para a medição das crenças de autoeficácia em um domínio é por meio de escalas de autoeficácia. Escalas de autoeficácia (BANDURA, 2006) são instrumentos construídos para avaliar as crenças dos indivíduos sobre suas capacidades de realizar determinadas açóes (itens da escala) de um domínio.

Segundo Bandura (2006, p. 314), “[...] o procedimento padrão para medir crenças pessoais de eficácia incluem um número de garantias para minimizar qualquer potencial efeito motivacional na autoavaliação." Algumas dessas garantias são: a) realizar uma boa análise do domínio; b) trabalhar crenças de forma multifacetadas, i.e. ${ }^{5}$, considerar domínios e subdomínios relacionados que possam influenciar as crenças; c) construir os itens da escala, variando em generalidade, força e nível; d) e garantir um intervalo de medição sensível ao domínio e ao perfil da amostra.

Considerando tais garantias, foi construída a Escala de Autoeficácia em Tecnologias e Computação (EATEC), uma escala para medir a autoeficácia de estudantes de ensino médio na tomada de decisóes por curso superior, com ênfase na computação e seu relacionamento com tecnologias no dia a dia. Essa escala traduz a confiança de estudantes sobre as suas capacidades de executar açóes associadas a esse domínio em valores, podendo ser utilizada para verificar se há disparidade nas crenças de autoeficácia das alunas do gênero feminino e alunos do gênero masculino, e se as crenças estáo adequadas quando comparadas às suas capacidades reais no domínio.

A escala elaborada contém 52 itens, divididos em cinco subdomínios relacionados: a) tomada de decisões (5 itens); b) escolha de curso superior (17 itens); c) aprendizagem escolar (9 itens); d) utilização e tecnologias (13 itens);

\footnotetext{
4 Por exemplo.

5 Isto é.
} 
e) e conhecimentos de computação (8 itens). Os itens da escala variam em generalidade das atividades e nível de dificuldade. A força da escala é medida por meio de respostas estruturadas em contínuo de 0 a 10, de acordo com a percepçáo da intensidade da autoeficácia pelas estudantes $(0$ - nada confiante, 5 - moderadamente confiante e 10 - totalmente confiante).

\subsection{Análise de confiabilidade da escala}

A fim de analisar a confiabilidade, i.e., a intensidade da correlação entre os itens da escala de autoeficácia, foi realizada uma aplicação piloto da escala com 14 alunas do primeiro ano do ensino médio de escolas públicas de Mato Grosso, com idades entre 14 e 16 anos. Optou-se pelo primeiro ano para verificar também se os itens estavam suficientemente claros para o perfil da escala.

A análise da confiabilidade foi testada por meio do coeficiente $\alpha$ de Cronbach (1951) executada no software estatístico R. A Tabela 1 apresenta todos os itens da escala de autoeficácia com seus respectivos valores de média, variância e coeficiente $\alpha$, de acordo com os dados da aplicação piloto.

Tabela 1 - Escala de Autoeficácia em Tecnologias e Computação (EATEC)

\begin{tabular}{|c|c|c|c|}
\hline \multicolumn{2}{|r|}{ ITENS DA ESCALA } & MÉDIA & VARIÂNCIA \\
\hline \multirow{7}{*}{ 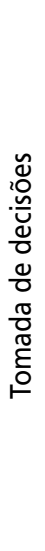 } & $\begin{array}{l}\text { Tomar decisões e fazer escolhas de acordo com o meu } \\
\text { desejo }\end{array}$ & 6,929 & 2,209 \\
\hline & $\begin{array}{l}\text { Tomar decisões e fazer escolhas de acordo com o } \\
\text { desejo de minha família ou um familiar }\end{array}$ & 6,857 & 6,265 \\
\hline & $\begin{array}{l}\text { Tomar decisões e fazer escolhas de acordo com o } \\
\text { desejo de meus(minhas) amigos(as) }\end{array}$ & 4,286 & 3,918 \\
\hline & $\begin{array}{l}\text { Tomar decisões e fazer escolhas com o apoio de minha } \\
\text { família ou um familiar }\end{array}$ & 8,429 & 4,816 \\
\hline & $\begin{array}{l}\text { Tomar decisões e fazer escolhas com o apoio de } \\
\text { meus(minhas) amigos(as) }\end{array}$ & 6,214 & 6,311 \\
\hline & \multicolumn{3}{|l|}{ Média Geral: 6,543 } \\
\hline & \multicolumn{3}{|l|}{ Coeficiente $\alpha: 0.744872$} \\
\hline
\end{tabular}




\begin{tabular}{|c|c|c|c|}
\hline \multicolumn{2}{|r|}{ ITENS DA ESCALA } & MÉDIA & VARIÂNCIA \\
\hline \multirow{19}{*}{ 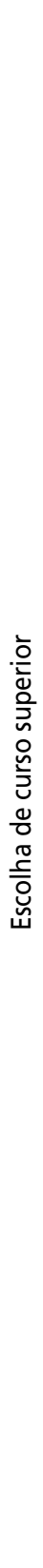 } & $\begin{array}{l}\text { Escolher um curso de nível superior para fazer após o } \\
\text { ensino médio }\end{array}$ & 8,429 & 3,388 \\
\hline & $\begin{array}{l}\text { Escolher um curso de nível superior de acordo com o } \\
\text { meu desejo }\end{array}$ & 8,786 & 3,454 \\
\hline & $\begin{array}{l}\text { Escolher um curso de nível superior de acordo com o } \\
\text { desejo de minha família ou um familiar }\end{array}$ & 4,429 & 7,102 \\
\hline & $\begin{array}{l}\text { Escolher um curso de nível superior de acordo com o } \\
\text { desejo de meus(minhas) amigos(as) }\end{array}$ & 1,857 & 4,837 \\
\hline & $\begin{array}{l}\text { Escolher um curso de nível superior com o apoio de } \\
\text { minha família ou um familiar }\end{array}$ & 8,214 & 6,597 \\
\hline & $\begin{array}{l}\text { Escolher um curso de nível superior com o apoio de } \\
\text { meus(minhas) amigos(as) }\end{array}$ & 5,714 & 11,061 \\
\hline & $\begin{array}{l}\text { Escolher um curso de nível superior de acordo com } \\
\text { uma boa perspectiva financeira da carreira }\end{array}$ & 6,571 & 7,388 \\
\hline & $\begin{array}{l}\text { Escolher um curso de nível superior de acordo com a } \\
\text { nota do ENEM/SISU }\end{array}$ & 6,357 & 5,372 \\
\hline & $\begin{array}{l}\text { Escolher um curso de nível superior de acordo com as } \\
\text { possibilidades financeiras pessoais e de minha família }\end{array}$ & 6,357 & 6,515 \\
\hline & $\begin{array}{l}\text { Escolher um curso de nível superior de acordo com as } \\
\text { minhas possibilidades de locomoção }\end{array}$ & 6,143 & 6,837 \\
\hline & $\begin{array}{l}\text { Escolher um curso de nível superior de acordo com as } \\
\text { expectativas da sociedade }\end{array}$ & 3,571 & 9,102 \\
\hline & $\begin{array}{l}\text { Escolher um curso de nível superior de acordo com } \\
\text { meu gênero }\end{array}$ & 3,857 & 10,837 \\
\hline & $\begin{array}{l}\text { Escolher um curso de nível superior relacionado à } \\
\text { computação, tecnologias ou engenharias }\end{array}$ & 5,500 & 8,393 \\
\hline & $\begin{array}{l}\text { Escolher um curso de nível superior da área de ciências } \\
\text { exatas }\end{array}$ & 4,429 & 14,102 \\
\hline & $\begin{array}{l}\text { Escolher um curso de nível superior da área de ciências } \\
\text { biológicas, agrárias ou da saúde }\end{array}$ & 5,214 & 13,597 \\
\hline & $\begin{array}{l}\text { Escolher um curso de nível superior da área de ciências } \\
\text { humanas ou sociais }\end{array}$ & 5,143 & 10,837 \\
\hline & $\begin{array}{l}\text { Escolher um curso de nível superior da área de } \\
\text { linguagem, linguística, letras ou artes }\end{array}$ & 3,143 & 8,837 \\
\hline & \multicolumn{3}{|l|}{ Média Geral: 5,513 } \\
\hline & \multicolumn{3}{|l|}{ Coeficiente $\boldsymbol{\alpha}: 0.8509835$} \\
\hline
\end{tabular}




\begin{tabular}{|c|c|c|c|}
\hline \multicolumn{2}{|r|}{ ITENS DA ESCALA } & MÉDIA & VARIÂNCIA \\
\hline \multirow{10}{*}{ 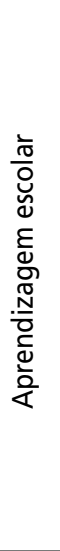 } & Aprender matemática & 7,286 & 6,204 \\
\hline & Aprender português & 7,286 & 2,204 \\
\hline & Aprender história & 7,071 & 2,923 \\
\hline & Aprender geografia & 7,500 & 2,536 \\
\hline & Aprender química & 5,643 & 6,087 \\
\hline & Aprender física & 5,286 & 4,061 \\
\hline & Aprender inglês & 7,429 & 4,245 \\
\hline & Aprender outro idioma (além do português e inglês) & 6,714 & 5,061 \\
\hline & Praticar atividades físicas & 7,214 & 7,597 \\
\hline & $\begin{array}{l}\text { Média Geral: } 6,825 \\
\text { Coeficiente } \boldsymbol{\alpha}: 0.8612459\end{array}$ & & \\
\hline \multirow{15}{*}{ 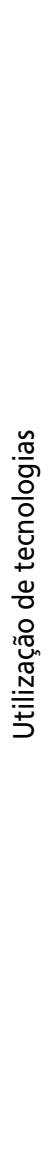 } & $\begin{array}{l}\text { Utilizar um celular para se comunicar com outras } \\
\text { pessoas (troca de mensagens, redes sociais, ligações, } \\
\text { etc.) }\end{array}$ & 8,500 & 3,964 \\
\hline & $\begin{array}{l}\text { Utilizar um celular para realizar buscas e pesquisas de } \\
\text { informações }\end{array}$ & 8,429 & 3,673 \\
\hline & $\begin{array}{l}\text { Utilizar um celular para manter-se atualizado com } \\
\text { notícias e novidades }\end{array}$ & 8,357 & 3,372 \\
\hline & Utilizar um celular para estudos e trabalhos escolares & 8,000 & 7,143 \\
\hline & Instalar e desinstalar aplicativos em um celular & 7,786 & 4,454 \\
\hline & Cuidar do bom funcionamento de um celular & 7,500 & 3,679 \\
\hline & $\begin{array}{l}\text { Gerenciar recursos de um celular, como memória, } \\
\text { armazenamento, conexões de redes e outras } \\
\text { configurações }\end{array}$ & 7,500 & 3,964 \\
\hline & $\begin{array}{l}\text { Utilizar computadores para buscas e pesquisas de } \\
\text { informações }\end{array}$ & 8,143 & 7,980 \\
\hline & $\begin{array}{l}\text { Utilizar computadores para manter-se atualizado com } \\
\text { notícias e novidades }\end{array}$ & 7,000 & 9,286 \\
\hline & $\begin{array}{l}\text { Utilizar computadores para estudos e trabalhos } \\
\text { escolares }\end{array}$ & 8,571 & 4,531 \\
\hline & Instalar e desinstalar programas em computadores & 6,571 & 6,816 \\
\hline & Cuidar do bom funcionamento de um computador & 7,500 & 3,107 \\
\hline & $\begin{array}{l}\text { Gerenciar recursos de um computador, como espaço } \\
\text { em disco, dispositivos conectados, conexões de redes e } \\
\text { outras configurações }\end{array}$ & 7,357 & 3,801 \\
\hline & \multicolumn{3}{|l|}{ Média Geral: 7,786 } \\
\hline & \multicolumn{3}{|l|}{ Coeficiente $\boldsymbol{\alpha}: 0.9328409$} \\
\hline
\end{tabular}




\begin{tabular}{|c|c|c|c|}
\hline \multicolumn{2}{|r|}{ ITENS DA ESCALA } & MÉDIA & VARIÂNCIA \\
\hline \multirow{10}{*}{ 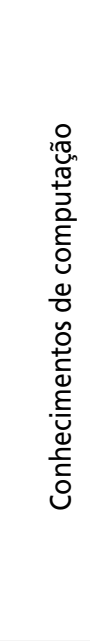 } & $\begin{array}{l}\text { Utilizar editores de texto, planilhas, apresentações e } \\
\text { outras ferramentas de escritório (office) }\end{array}$ & 6,571 & 9,673 \\
\hline & Utilizar uma linguagem de programação & 2,857 & 8,837 \\
\hline & Utilizar duas ou mais linguagens de programação & 2,357 & 6,658 \\
\hline & $\begin{array}{l}\text { Aplicar conceitos básicos de robótica, arduíno ou } \\
\text { eletrônica }\end{array}$ & 2,571 & 7,673 \\
\hline & Gerenciar redes & 2,857 & 6,551 \\
\hline & $\begin{array}{l}\text { Administrar computadores pelo modo de linha de } \\
\text { comando }\end{array}$ & 1,929 & 5,638 \\
\hline & Manipular banco de dados & 2,000 & 6,000 \\
\hline & Aprender novos conhecimentos sobre computação & 8,071 & 6,923 \\
\hline & Média Geral: 3,652 & & \\
\hline & Coeficiente $\alpha: 0.9060898$ & & \\
\hline \multicolumn{4}{|c|}{ TODOS OS ITENS DA ESCALA } \\
\hline \multicolumn{4}{|c|}{ Média Geral: 5,921 } \\
\hline \multicolumn{4}{|c|}{ Coeficiente $\alpha: 0.9402098$} \\
\hline
\end{tabular}

Fonte: Elaboração dos autores

No que se refere à confiabilidade dos dados, o coeficiente $\alpha$ de Cronbach encontrado para a escala EATEC com os dados da aplicação piloto foi de 0.9402098, valor extremamente satisfatório, tendo em vista que quanto mais próximo de 1 maior a confiabilidade entre os indicadores. Os itens encontrados com a maior variância são: 11, 17, 19, 20 e 21. Entretanto, optou-se por não realizar a purificação da escala com a remoção desses itens por considerá-los relevantes para a medição e o alto impacto do coeficiente $\alpha$ já encontrado. Dessa forma, é possível afirmar que a EATEC é confiável para a avaliação da autoeficácia na tomada de decisóes por curso superior, com ênfase na computação e seu relacionamento com tecnologias no dia a dia, com estudantes de ensino médio.

\subsection{Resultados preliminares}

$\mathrm{Na}$ aplicação piloto da escala, é possível observar o valor relativamente baixo da autoeficácia geral para tomada de decisóes e relacionamento com tecnologia das estudantes participantes (média geral: 5,921).

Analisando o subdomínio de escolha de curso superior (média 6,543, coeficiente $\alpha: 0.744872$ ), nota-se que a autoeficácia média das entrevistadas é menor que para 
o subdomínio de tomada de decisões em geral (média geral: 5,513, coeficiente $\alpha$ : 0.8509835), revelando as inseguranças das alunas na área da carreira. Também é notável o valor que as alunas dão à participação e ao apoio da família nas decisóes em geral e na escolha de um curso superior (itens 4, 7 e 10), diferente da participação dos amigos e amigas no mesmo cenário (itens 3, 5, 9 e 11).

Apesar de apontarem o baixo valor do gênero em sua escolha por um curso superior (item 17), é preciso lembrar, conforme discutido neste trabalho, que as influências do gênero se dão em todas as relaçóes da tríade do determinismo recíproco, considerando não somente fatores pessoais, mas também fatores comportamentais e contextuais em que os indivíduos estáo inseridos, abrangendo as relações interpessoais das alunas (e suas influências familiares).

O subdomínio de utilização de tecnologias apresenta os valores médios mais altos (média geral: 7,786,coeficiente $\alpha$ : 0.9328409), em oposição ao subdomínio de conhecimentos de computaçáo, que apresenta os valores médios mais baixos (média geral: 3,652, coeficiente $\alpha$ : 0.9060898). Esse fato é interessante e revela como as alunas possuem uma autoeficácia elevada para o consumo de tecnologias, enquanto exibem uma autoeficácia baixa para as atividades de produção tecnológica, mesmo em atividades mais simples, como as de edição de textos (item 45). Outro fato curioso é que quando indagadas sobre sua confiança em aprender novos conhecimentos sobre computação (item 52) a resposta é positiva (média: 8,071, variância: 6,923) e uma das mais elevadas se comparada aos demais itens da escala, mais alta inclusive que a aprendizagem escolar em todas as áreas questionadas.

Tais achados são condizentes com as suposições teóricas de que as meninas têm interesse em aprender mais sobre tecnologia, muito embora tenham menos oportunidades de exposição às atividades do domínio computacional/tecnológico, e que talvez quando essas oportunidades aconteçam elas vivam experiências de aprendizagem que influenciem negativamente as suas crenças de autoeficácia. Todavia, é necessário realizar uma nova aplicação da escala com uma amostra maior, cruzando os dados com outros métodos qualitativos para poder confirmar essas suposiçóes e tirar conclusôes mais significativas.

\section{Considerações Finais}

Este artigo discutiu a influência dos gêneros no desenvolvimento de carreira e a relação com computação e tecnologias a partir de uma perspectiva teórica da Psicologia do desenvolvimento da carreira e seus entrelaçamentos, com ênfase no papel das crenças de autoeficácia. 
Compreender como a autoeficácia é consolidada de forma diferente pelos gêneros no desenvolvimento da carreira ajuda a fornecer subsídios para projetar programas que atendam às necessidades de alunas e alunos durante esse período. A análise da autoeficácia é útil para desenvolver sistemas de apoio sem estereótipos de gênero em domínios não tradicionais, como a computação.

Dessa forma, uma das principais contribuiçóes desta pesquisa foi a construção da Escala de Autoeficácia em Tecnologias e Computação (EATEC), instrumento desenvolvido para estudantes de ensino médio com o intuito de medir sua confiança em aspectos da tomada de decisóes por curso superior, com ênfase na computaçáo e seu relacionamento com tecnologias no cotidiano.

A EATEC foi aplicada e validada a partir de uma pilotagem com 14 alunas de ensino médio, que obteve uma confiabilidade $\alpha$ de Cronbach alta. Isso revela que o instrumento é adequado ao que se propóe a medir e que a EATEC pode ser empregada no futuro para mensurar a autoeficácia de alunas e alunos de ensino médio com relação ao uso e conhecimento de tecnologias e à aspectos da tomada de decisão de curso superior. Os resultados da EATEC podem ser utilizados para estimar se há diferenças entre os gêneros, bem como para outros possíveis recortes (socioeconômico, racial, etc.), e também para identificar os itens mais importantes para serem trabalhados individualmente ou com o grupo avaliado.

Segundo Bandura (2006, p. 319), “[...] o valor da teoria psicológica é julgado não somente pelo seu poder explicativo e explanatório, mas também pelo seu poder operatório de efetuar mudanças." Assim, conhecer como se desenvolve e opera a autoeficácia entre adolescentes no campo computacional e tecnológico oferece contribuiçóes para estruturar experiências que permitam realizar os seus desejos individuais, e, até mesmo, propiciar mudanças sociais na área.

\section{Referências}

AMÂNCIO, Lígia. As assimetrias nas representações do género. Revista Crítica de Ciências Sociais, Coimbra, v. 34, p. 9-22, 1992.

BANDURA, Albert. Social-learning theory of identificatory processes. Handbook of socialization theory and research, Nova Iorque, v. 213, p. 262, 1969.

BANDURA, Albert. Social foundations of thought and action: a social cognitive theory. Englewood Cliffs, NJ: Prentice Hall, 1986.

BANDURA, Albert. Human agency in social cognitive theory. American psychologist, Filadélfia, v. 44, n. 9, p. 1175-1184, 1989. 
BANDURA, Albert. Self-efficacy in changing societies. New York: Cambridge University Press, 1995. 334p.

BANDURA, Albert. Social cognitive theory of personality. In: PERVIN, L.; JOHN, O. P. (Ed.). Handbook of personality. New York: Guilford Publications, 1999. p. 154-196.

BANDURA, Albert. Guide for constructing self-efficacy scales. In: PAJARES, Frank; URDAN, Timothy C. (Ed.). Self-efficacy beliefs of adolescents, Greenwich, CT: IAP, 2006. p. 307-337. v. 5.

BEHJAT, Saeed; CHOWDHURY, Mohammmed S. Emotional intelligence, self-efficacy and diversity receptiveness of university students: a correlation study. International Journal of Academic Research in Business and Social Sciences, Raipur, v. 2, n. 4, p. 301, 2012.

BETZ, Nancy E.; HACKETT, Gail. The relationship of career-related selfefficacy expectations to perceived career options in college women and men. Journal of counseling psychology, College Park, v. 28, n. 5, p. 399-410, 1981.

BROWN, Duane. Introduction to Theories of Career Development and Choice: origins and Current Efforts. In: BROWN, D. and associates. Career Choice and Development. 4th ed. San Francisco, CA: The Jossey-Bass business, 2002.

CHOI, Jin Nam; PRICE, Richard H.; VINOKUR, Amiram D. Self-efficacy changes in groups: effects of diversity, leadership, and group climate. Journal of Organizational Behavior, Nova Jersey, v. 24, n. 4, p. 357-372, 2003.

COMBS, Gwendolyn M.; LUTHANS, Fred. Diversity training: analysis of the impact of self-efficacy. Human Resource Development Quarterly, Indianapolis, v. 18, n. 1, p. 91-120, 2007.

CRONBACH, Lee J. Coefficient alpha and the internal structure of tests. Psychometrika, Nova Iorque, v. 16, n. 3, p. 297-334, 1951.

DEAUX, Kay. From individual differences to social categories: Analysis of a decade's research on gender. American Psychologist, Filadélfia, v. 39, n. 2, p. 105, 1984.

DUCHATELET, Dorothy el al. Exploring students' differences of motivation, interest and self-efficacy in a cross-continental simulation context. In: 2nd TEACHING AND LEARNING CONFERENCE, June 9-10, 2016, Brussels, Belgium, p. 1-17, 2016.

FITZGERALD, Louise F.; FASSINGER, Ruth E.; BETZ, Nancy E. Theoretical advances in the study of women's career development. In: WALSH, W.; OSIPOW, 
S. H. Career counseling for women. Nova Jersey: Lawrence Erlbaum Associates, Inc., 1995. p. 67-109.

HARDING, Sandra G. The science question in feminism. Nova Iorque: Cornell University Press, 1986. 271p.

HARTSOCK, Nancy. Foucault on power: a theory for women? In: NICHOLSON, L. J. (Ed.). Feminism/Postmodernism. London: Routledge, 1990. p. 157-175.

INSTITUTO NACIONAL DE ESTUDOS E PESQUISAS EDUCACIONAIS ANÍSIO TEIXEIRA (INEP). Resumo Técnico da Educaçáo Superior 2013. Diretoria de Estatísticas Educacionais - DEED, Instituto Nacional de Estudos e Pesquisas Educacionais Anísio Teixeira, Brasília, DF, 2015. 82p.

KARWOWSKI, Maciej; KAUFMAN, James C. (Ed.). The Creative Self: effect of Beliefs, Self-Efficacy, Mindset, and Identity. Cambridge: Academic Press, 2017.

LENT, Robert W.; BROWN, Steven D.; HACKETT, Gail. Toward a unifying social cognitive theory of career and academic interest, choice, and performance. Journal of vocational behavior, Amsterdâ, v. 45, n. 1, p. 79-122, 1994.

LENT, Robert W.; BROWN, Steven D.; HACKETT, Gail. Social cognitive career theory In: BROWN. In: BROWN, D. and associates. Career Choice and Development. 4th ed. San Francisco, CA: The Jossey-Bass business, 2002. p. 255-311.

PLANT, Sadie. Zeros and ones. Nova Iorque: Doubleday Books, 1997.

PORTAL BRASIL. Mulheres são maioria no ingresso e na conclusão de cursos superiores. Educaçáo, 8, mar. 2015. Disponível em: <http://www.brasil.gov.br/ educacao/2015/03/mulheres-sao-maioria-no-ingresso-e-na-conclusao-de-cursossuperiores $>$. Acesso em: 1 jun. 2017.

PRISCO, Ana Paula Kalil; MARTINS, Cíntia Ribeiro; NUNES, Maiana Farias Oliveira. Estudos sobre autoeficácia aplicada ao desenvolvimento de carreira no Brasil: uma revisão. Revista Brasileira de Orientaçáo Profissional, Florianópolis, v. 14, n. 1, p. 111-118, 2013.

ROJEWSKI, Jay W.; YANG, Baiyin. Longitudinal analysis of select influences on adolescents' occupational aspirations. Journal of Vocational Behavior, Amsterdã, v. 51, n. 3, p. 375-410, 1997.

SAAVEDRA, Luísa. Assimetrias de Género nas Escolhas Vocacionais. Guiáo de educaçáo - Género e cidadania. Lisboa: CIG, 2009. 
SAAVEDRA, Luísa; TAVEIRA, Maria do Céu; SILVA, Ana Daniela. A subrepresentatividade das mulheres em áreas tipicamente masculinas: factores explicativos e pistas para a intervenção. Revista Brasileira de Orientação Profissional, Florianópolis, v. 11, n. 1, p. 49-59, 2010.

TAVEIRA, Maria do Céu. Exploraçáo e desenvolvimento vocacional de jovens. Minho, Portugal: Centro de Estudos em Educação e Psicologia, Universidade do Minho, 2000.

TAVEIRA, Maria do Céu; NOGUEIRA, Conceição. Estudos de género e Psicologia vocacional: confronto de teorias e implicaçóes para a intervençáo vocacional. In: COELHO, Helena; OLIVEIRA, Helena; LEONARDO, Joana. Desenvolvimento vocacional ao longo da vida: fundamentos, princípios e orientaçóes. Coimbra: Almedina, 2004. p. 57-81.

TIMS, Maria; B. BAKKER, Arnold; DERKS, Daantje. Daily job crafting and the self-efficacy-performance relationship. Journal of Managerial Psychology, Bingley, v. 29, n. 5, p. 490-507, 2014. 